\title{
Ler Judith Butler: sujeito, desidentificação, performatividade
}

\author{
Reading Judith Butler: \\ subject, desidentification, performativity
}

\author{
Mariana Pimentel Fischer \\ Docente do departamento de direito da UFPE
}

Resumo: As teses de Judith Butler são centrais para o debate atual sobre filosofia política, mas nem sempre têm sido bem compreendidas por militantes ou por acadêmicos. As dificuldades de entendimento parecem estar conectadas ao estilo de escrita, assim como a diversidade de perspectivas que a filósofa mobiliza. Busco, neste artigo, tonar mais clara a maneira pela qual Butler reconstrói ideias da tradição francesa com o objetivo de elaborar conceitos centrais para seu projeto critico tais como sujeito, identidade, agência e performatividade.

Palavras-chave: sujeito, desidentificação, performatividade, gênero, pós-estruturalismo.

Abstract: Judith Butler's theses are crucial to the contemporary debate on political philosophy. Her ideas, however, have not always been well understood by activists or scholars. These difficulties are related to her writing style as well her constant allusions to other theorists drawn from a wide range of different theoretical traditions. In this article, I will try to clarify how Butler reconstructs ideias from 
French Theory in order to elaborate central concepts for her perspective such as subject, identity, agency and performativity.

Keywords: subject, desidentification, performativity, gender, post-structuralism

\section{Um estilo de escrita pesado e obscuro?}

O pensamento da filósofa norte-americana Judith Butler nem sempre tem sido bem compreendido por militantes (cf. MANZI \& SCOFANO, 2015) ou por acadêmicos. Martha Nussbaum (1999), por exemplo, faz fortes críticas a seu estilo de escrita, que seria "pesado e obscuro (...) denso em menções a outros teóricos, recrutados de um amplo espectro de tradições distintas" (p. 38), diversos pensadores seriam mencionados em "alusões casuais" (p. 38) e, assim, suas ideias "nunca são descritas com detalhes suficientes para incluir não iniciados" (p. 38). Butler (1999b), por seu turno, convoca Herbert Marcuse para dar uma contundente resposta a Nussbaum: segundo ela, filósofos comprometidos em realizar uma crítica radical não falam como as outras pessoas, pois seu discurso pressupõe o colapso do universo discursivo e comportamental para o qual se pretende traduzi-lo (BUTLER, 1999b).

Mesmo se concordarmos que há bons motivos para isso, não há como negar que os textos da norte-americana não são de fácil compreensão. O meu propósito, nesse artigo, é justamente desfazer mal-entendidos e ajudar aqueles que pretendem começar a ler os seus trabalhos. Para tanto, apresentarei alguns aspectos relevantes de sua trajetória e tentarei mostrar como ela mobiliza a tradição francesa com objetivo a elaborar conceitos centrais para o seu projeto, tais como sujeito, identidade, agência e performatividade.

Butler é uma pensadora heterodoxa. Não apenas em razão das recorrentes associações inusitadas entre pensadores de linhagens distintas, mas também por conta da maneira que conecta teoria e prática. O seu percurso intelectual extrapola os limites estritos da academia, envolve também uma intensa 
militância política, principalmente em defesa de direitos das mulheres, de gays e de lésbicas. Ela se esforça para pensar lado a lado teoria e a ação de movimentos sociais: se as práticas devem conduzir a uma reconfiguração de conceitos da teoria, a teoria pode também ajudar militantes a realizar uma autocrítica. Nessa toada, desconfia de certas vertentes do feminismo, sobretudo as que insistem na centralidade de identidades; mas, ainda assim, afirma que sua teoria faz parte da tradição feminista (cf. BUTLER, 1999a).

Ora, tal desconfiança com relação ao papel de identidades não deve surpreender. Seu empreendimento crítico está afinado ao projeto de filósofos como Michel Foucault e Theodor Adorno, já que "O julgamento opera para ambos como forma de subsumir um particular em uma categoria já constituída; a crítica pergunta pela constituição desses campos de categorias" (BUTLER, 2002, p. 218). Em lugar de prescrever algum tipo de modelo de vida; Butler, tal como o frankfurtiano e o francês, está mais interessada em desfazer (Undo) a lógica que determina que vidas são possíveis ou impossíveis, vivíveis ou invivíveis, e, assim, abrir espaço para alternativas radicalmente novas. $\mathrm{O}$ seu propósito é, portanto, colocar em questão o quadro normativo que organiza nosso modo de experimentar o mundo. Adorno insistia que as questões referentes à eticidade podem apenas surgir, na vida social, no momento em que as normas deixam de ser auto-evidentes. Para a filósofa, trata-se reinscrever esse projeto no contexto do debate atual sobre feminismo, ela enfatiza, portanto, o papel de uma crítica imanente capaz de provocar um reexame do vocabulário da tradição feminista e impulsionar a sua reconstrução (cf. ADORNO, 2000; BUTLER, 2005).

Suas primeiras publicações, no inicio da década de 1980, demonstram uma preocupação constante com formas de atualização da filosofia hegeliana na França. Autoras e autores como Simone de Beauvoir, Merleau-Ponty e Jacques Lacan, ajudam-na a refletir sobre o problema da constituição do sujeito e sua relação com a alteridade (cf. BUTLER, 1987). Esses mesmos temas são reformulados de maneira original em Problemas de Gênero (1990), que se tornou um dos textos fundadores da Teoria Queer norte-americana - um campo de estudos e práticas 
que ganhou força em meados da década de 1990 nos EUA e que pretende desnaturalizar concepções socialmente arraigadas sobre gênero de modo a investigar formas de ação política que não mais se apoiam em identidades. A partir de meados da década de 2000, há uma mudança de ênfase em sua perspectiva. Em vez de questões específicas sobre gênero, a tônica passa a recair sobre um tema mais geral, a precarização (cf. BUTLER, 2004b, 2005, 2009, 2013, 2015). O interesse em elaborar uma teoria do sujeito que carrega em si o outro (como dizem autoras e autores de linhagem hegeliana), sua relação com identidades, assim como o papel da performatividade e da agência se mantem, contudo, constante em toda sua trajetória intelectual. Para ela, é fundamental perguntar pela possibilidade de agência em um sujeito já desde sempre está emaranhado a determinações da vida social.

\section{Franceses nos EUA}

Butler (1999a) escreve: "Problemas de Gênero é baseado na 'Teoria Francesa', a qual é uma curiosa construção norte-americana" (p. x). De fato, pensadoras e pensadores que para os franceses pouco tem em comum, no contexto norte-americano são frequentemente interpretados de maneira interligada, como parte de uma mesma tradição. Não por acaso, portanto, sua leitura sofre objeções daqueles que insistem que a teoria da filósofa seria demasiadamente eclética e pouco fiel aos escritos de autores tão diversos como Foucault e Jacques Derrida. Butler (1999a) responde que seu trabalho não deve ser compreendido como uma tentativa de reproduzir com fidelidade as teses dos teóricos que utiliza, deve sim ser lido como um esforço de tradução cultural. Para ela, mudanças enriquecedoras na teoria podem ocorrer por meio de novas apropriações. A defesa de uma tradução cultural e de um inesgotável processo de reconstrução da teoria está na base do pensamento de Butler, que insiste ainda que a tarefa da crítica não deve ser simplesmente aplicar o pensamento francês ao feminismo, mas reformular ideias em jogo naquele contexto tendo em conta problemas referentes a lutas sociais atuais. 
Lembremos, então, que expressões como pós-estruturalismo ou tradição francesa são utilizadas para fazer referência, de maneira bastante genérica, a pensadoras e pensadores que, notadamente, a partir da década de 1950, na França, buscaram dar um passo além do estruturalismo de Ferdinand Saussure e de Claude Lévi-Strauss. Em 1916, Saussure afirmou haveria uma estrutura (isto é, uma forma constante) que estabeleceria as relações entre os elementos de toda e qualquer língua. Posteriormente, o antropólogo Lévi-Strauss tentou identificar as estruturas que determinariam a reprodução de significados em atividades de diversos grupos humanos, como rituais religiosos, jogos e hábitos alimentares. Uma importante provocação sobre o papel da mulher na sociedade é feita por Lévi-Strauss. Para ele, as sociedades se formam com base em uma Lei que proíbe o incesto e que, concomitantemente, funda a exogamia (o casamento entre membros de clãs diferentes) e estabelece para as mulheres o papel de objeto de troca: "na sociedade humana um homem deve obter uma mulher de outro homem, que lhe dá uma filha ou irmã (...) os homens que trocam a mulheres, e não o contrário" (LEVI-STRAUSS, 1982, p. 154). Lévi-Strauss já indicava, assim, que existem normas que, sem que possamos perceber, organizam nosso modo de vida e, especialmente, estabelecem um peculiar papel para as mulheres.

O trabalho destes dois autores instigou a investigação de Maurice Merleau-Ponty, Simone de Beauvoir, Michel Foucault, Jacques Lacan e Jacques Derrida, que não cessaram de indagar: existem, de fato, determinações linguísticas constantes que organizam nossa língua e nosso modo de vida? Há estruturas que impulsionam não só nossas relações mais diretas de parentesco, como também nossas relações de trabalho e com o Estado? Falamos ou "somos falados" pela linguagem? Particularmente aqueles que se interessaram por temas ligados à feminilidade perguntaram pelo lugar da mulher em uma estrutura simbólica que nos precede. Se Lévi-Strauss estiver certo (ou se sua explicação for útil, ao menos, para explicar a formação de sociedades patriarcais), como podemos transformar esse papel de objeto de troca estabelecido para mulher? Nesse sentido, autores de trajetória bastante distinta como Simone de Beauvoir e 
Jacques Lacan ${ }^{63}$, cada um a seu modo, mostram a importância de manter a pergunta "o que é uma mulher?".

Se a função da fêmea não basta para definir a mulher, se nos recusamos também explicá-la pelo "eterno feminino" e se, no entanto, admitimos, ainda que provisoriamente, que há mulheres na terra, teremos que formular a pergunta: que é uma mulher? (BEAUVOIR, 1970, p. 9).

Em especial a partir da década de 1960, as lutas feministas passaram a se organizar por meio de demandas identitárias. Parecia ser preciso estabelecer especificidade do gênero feminino assim como as peculiaridades de um feminismo negro ou lésbico para organizar combates contra a opressão. Levar as teses debatidas no contexto do pós-estruturalismo a sério significa, todavia, conservar a pergunta "o que é uma mulher?". E se não pudermos definir o que é uma mulher, como poderemos lutar contra a dominação? E se não nos apoiarmos em uma identidade (ou em identidades), como, então, poderemos agir politicamente? Eis os desafios de um feminismo que pretende ultrapassar as fronteiras do próprio feminismo.

\section{Gênero, performatividade e agência}

Butler recepciona a legado estruturalista ao afirmar que existem imposições linguísticas que nos precedem e, ao menos em parte, determinam nossas vidas. Essas imposições estabelecem, sem que possamos nos dar conta, normas que formam a maneira pela qual atuamos o gênero. Afirmações como "sou um homem" ou "sou uma mulher", que parecem ser descrições daquilo que irrevogavelmente somos, sub-repticiamente estabelecem prescrições. Elas dissimulam sua força normativa, isto é, a maneira pela qual impõem como devemos agir para que possamos nos enquadrar em uma das duas possibilidades previamente definidas para o gênero, assim "as operações de poder que governam o gênero são fugidias, elas se referem ao que 'deve ser o caso' sob a rubrica 'do que é o caso'” (BUTLER, 1999a, p. xxi).

$63 \quad$ Para Lacan não existe "a" mulher, podemos somente falar em singularidades, isto é, em mulheres. Ver, principalmente, o Seminário. Livro 20 (1985). 
O grande obstáculo para pensarmos as normas de gênero reside, portanto, na dificuldade que temos de percebê-las como tal. Com o auxílio da psicanálise de Sigmund Freud e Jacques Lacan, Butler mostra que não conseguimos enxergar as normas, pois elas estão ao mesmo tempo fora e dentro: nós as introjetamos e as naturalizamos (cf. BUTLER, 1993, 1999a, 2000). Aquilo que tomamos como um atributo que nos seria interno é, entretanto, algo que nós antecipamos e produzimos por meio de atos corporais. O gênero pode ser compreendido, assim, como um "efeito alucinatório de gestos naturalizados" (BUTLER, 1999a, p. xv).

Se, tal como os estruturalistas, Butler percebe que somos governados por normas que nos precedem; ela vai além do estruturalismo ao encontrar um modo muito particular de mostrar que esta determinação não é completa. Para ela, há, ainda assim, liberdade, ou, se quisermos usar uma expressão frequente no debate norte-americano, agência (agency). O ponto nevrálgico aqui é: o potencial para liberdade está justamente nas normas que governam a nossa ação. Não é possível simplesmente deixarmos as normas para trás, pois elas nos constituem. Como diz Foucault, o sujeito é o efeito das normas. Butler ressalta, todavia, que apesar de ter afirmado que há práticas de sujeição e, do mesmo modo, de liberdade; Foucault não desenvolveu suficientemente suas formulações sobre os modos específicos em que a autonomia pode ocorrer. A filósofa explora esse caminho por meio de suas reflexões sobre performatividade: segundo ela, podemos repetir e, ao mesmo tempo, transformar. Como disse, o conceito de performatividade é de fundamental importância para sua teoria. Não é um exagero afirmar que as diversas reconfigurações e novas associações feitas em torno dessa noção ao longo de sua trajetória constituem o aspecto mais original de seu trabalho

Alguns defendem que gênero é biológico e outros que é construído culturalmente; Butler propõe um terceiro caminho: gênero é, para ela, performativo. Para sustentarmos um lugar que nos é atribuído por asserções como "és um homem" ou "és uma mulher", temos de realizar determinados gestos, temos 
que nos vestir de certa maneira, ou seja, temos de realizar uma performance. Algo semelhante ao que ocorre no teatro. É como se estivéssemos nos apresentando a um público. Diferentemente do teatro, entretanto, aqueles cuja atuação não condiz com as normas de gênero podem sofrer diversas formas de punição social, tal como nos casos de violência contra homossexuais, transgêneros, travestis e intersexuais. Gênero é performativo no sentido de que a essência, identidade ou realidade natural que atos e gestos que indicam o gênero parecem expressar são, na verdade, fabricações, que se configuram por meio da repetição e citação de atos realizados por outros no passado (cf. BUTLER, 1993, 1999a, 2013).

As bases de seus argumentos residem, sobretudo, em teses Derrida (cf. DERRIDA, 1988). Ela lembra leitura de "Diante da Lei", de Kafka, feita por Derrida:

Há aquele que espera pela lei, aguarda sentado diante das portas da lei, atribui uma certa força a lei pela qual espera. Antecipação de um desvelamento de sentido autoritário é a maneira pela qual a autoridade é atribuída e instalada: a antecipação conjura o objeto (1999a, p xiv).

A filósofa rastreia, ainda, a crítica de Derrida a John Austin e mostra as dificuldades de pensar a performance a partir de um ato ilocucionário que executa a ação apenas no momento de sua enunciação. Um discurso de ódio, por exemplo, tem efeitos corporais imediatos; possui, todavia, igualmente, efeitos que se prolongam no tempo, os quais são produzidos pela reiteração: para que a ofensa se materialize, ela precisa ser repetida. $O$ fato de que os efeitos de uma enunciação são diferidos no tempo e que exigem reiteração implica na impossibilidade se sustentar indefinidamente sua condição original. A reprodução produz necessariamente falhas ou excessos na norma. Essas fraquezas da norma podem ser trabalhadas de maneira a criar um excedente de significação. Reside aí a possibilidade de agência. Butler afirma: "isso é política então, essa abertura (para repetir diferentemente). Não a possiblidade de não repetir, mas possibilidades que se referem ao como e ao onde" (BUTLER, 1999c, p. 160.) Importa olhar para o contexto 
e para a maneira pela qual a reiteração ocorre, pois cada vez que é reencenada, uma enunciação pode ser transformada.

a verdadeira tarefa é descobrir como um sujeito que é constituído no e pelo discurso, recita o mesmo discurso, mas, talvez para um outro propósito. Para mim, a questão sempre foi sobre como encontrar agência, o momento da nova citação ou do replay do discurso que a condição da emergência de um sujeito (BUTLER, 1999c, p. 165).

A palavra queer nos EUA, por exemplo, na década de 1980, tinha um sentido pejorativo, era utilizada para insultar a população LGBTT (de maneira semelhante a expressão "bicha" no Brasil). Na década de 1990, contudo, especialmente na Califórnia, ativistas engajados à Teoria Queer insistiram em repetir a palavra em outro contexto e a seu modo, forçando a constituição de outro sentido. Por conta de tais práticas, o vocábulo queer hoje, na maior parte dos EUA, perdeu sua conotação pejorativa, é utilizado para se referir a pessoas que não se enquadram bem em qualquer referência conhecida para o gênero, frequentemente, a pessoas que parecem ser interessantes e que atiçam a curiosidade. No Brasil, há, hoje, tentativas de reconfigurar tal estratégia tendo em conta as particularidades do País; fala-se, aqui, em Teoria Bicha (cf. TAKARA, 2017; COOLING, 2012).

A ideia central é a de que uma transformação social pode ser impulsionada por ocorrências que mostram que aquilo que parecia ser uma realidade natural e auto-evidente é, na verdade, manufaturado: deformidades no gênero, falhas na repetição ou repetições paródicas. A performatividade aponta para processos que produzem aquilo que percebemos como realidade. Mas não apenas isso. Abre também espaço para o desfazimento da realidade tal como conhecemos (cf. BUTLER, 1993, 1997 1999a, 2013, 2015).

A agência, para a filósofa, está localizada justamente nesse jogo performativo de reiterações repleto de paradoxos. Trata-se, assim, de enfatizar práticas capazes de desfazer imposições normativas que estabelecem limites à nossa imaginação e que, uma vez e de novo, determinam um sentido bastante restrito para aquilo que compreendemos como possibilidades de mudança social. Butler (1999c) escreve: "penso que não se 
pode trabalhar com a teoria política sem um senso de imprevisibilidade, sem antecipar uma ruptura com o regime atual a qual não pode ser conhecida no presente. Estou sempre buscando essas rupturas" (p. 162).

Como disse, a noção de performatividade foi, por ela, algumas vezes reformulada. Mais recentemente, no livro Notes towards a performative theory of assembly (2015), Butler pergunta como a performatividade pode ser pensada coletivamente e ressalta a relevância de um direito à assembleia (right to assembly) ou um direito à presença de corpos em ruas ou praças. Diferentemente do modelo comunicacional habermasiano, a norte-americana interessa-se, portanto, pelo o fato de que a presença de corpos que se reúnem em espaços públicos tem efeitos performativos, que sempre extravasam a intencionalidade.

\section{Politica e desidentificação}

Parece que agora é possível perceber com mais clareza a estratégia que utiliza para ultrapassar o estruturalismo: "dizem-nos que a regra que proíbe o incesto é universal, mas Lévi-Strauss reconhece que ela não 'funciona' sempre. Ele não investiga, contudo, quais são as suas formas de não funcionamento" (BUTLER, 2000, p. 17). Butler ressalta que as normas produzem funcionalidade e conformidade na vida social, mas, ao mesmo tempo, geram necessariamente práticas disfuncionais, formações sociais que as excedem e expõem suas falhas. Mudanças profundas podem ocorrer por meio da mobilização destes pontos excessos ou deficiência.

A heterossexualidade oferece posições sexuais normativas que são intrinsecamente impossíveis de incorporar e a falha persistente em identificar-se plenamente e sem incoerência com essas posições revela que a heterossexualidade ela mesma é não só uma lei obrigatória como também uma comédia inevitável. De fato, este insight sobre heterossexualidade (como sistema obrigatório e comédia intrínseca, uma paródia constante de si mesma) estabelece uma perspectiva gay/lésbica alternativa (BUTLER, 1999a, p. 155).

Por esta razão, Butler se interessa, por exemplo, pela atuação de drag queens. Na performance das drags a identifica- 
ção de gênero acontece como uma paródia: a drag mostra que o gênero é uma imitação, ou melhor, uma imitação da imitação. A filósofa anota: "a paródia do gênero revela que a identidade original a partir da qual o gênero se estiliza é uma imitação sem origem" (1999a, p. 175).

Ao realizar performances que imitam mulheres idealizadas em nossa cultura, tal como as divas de Hollywood, a drag revela a falha que as divas tentam a qualquer custo esconder: nem mesmo a mulher que encarna a diva é capaz de alcançar o modelo ideal que a sua imagem tenta sustentar. Há, ainda, algo de melancólico na performance da drag, algo que nos mostra que houve uma perda (desse lugar idealizado) que não foi bem elaborada.

Poderemos compreender melhor a importância dessas reflexões se lembrarmos como a busca por um enquadramento identitário ou por alcançar uma imagem idealizada determina visceralmente, hoje, o nossa maneira de atuar o gênero. Parece que esse ideal que as divas de Hollywood tentam encarnar é um dos fatores que impulsionam tantas mulheres, em nossa cultura, a se submeter a uma quantidade exagerada de cirurgias estéticas, as quais podem até mesmo colocar suas vidas em risco. Lembremos também que tem se tornado cada vez mais frequente a realização de procedimentos cirúrgicos de mudança de sexo. Butler fornece especial atenção a esta última questão. Se, de um lado, ela percebe que, para alguns, a realização destas cirurgias é a única forma de tornar suas "vidas vivíveis"; de outro lado, ela também tem em conta os riscos e os casos de arrependimento. Não podemos esquecer que há um preço a pagar pela procura por um enquadramento sem ambivalências em uma das duas possibilidades para o gênero (cf. BUTLER, 1993, 1999a, 2004).

Imagens e identidades, as quais parecem ser, cada vez mais, fortalecidas em nosso modo de vida, podem esmagar o sujeito, que não cessa de tentar alcançar um lugar que é, por definição, inalcançável e, dessa maneira, encontra-se impedido de descobrir uma forma singular de viver. Talvez a crítica seja capaz de suavizar o peso de tais identidades e idealidades. Talvez, se este peso for diminuído, os sujeitos se sintam 
menos compelidos a realizar tantas intervenções cirúrgicas ou de diversas maneiras se manter em uma busca obstinada por alcançar ideais ou se enquadrar em modelos pré-estabelecidos para o gênero.

A crítica à identidade ganha um sentido mais específico na medida em que a filósofa conecta a lutas sociais. Movimentos sociais, como o movimento feminista ou o movimento negro, utilizam frequentemente identidades para articularem suas demandas. Eles creem precisar dizer o que significa ser mulher ou ser negro para falar sobre a especificidade da opressão que sofrem e, assim, reivindicar mudanças. Esta questão tem especial relevância para perspectivas feministas atuais, que ressaltam a importância de pensar as diversas características e diferentes demandas de mulheres negras e mulheres trans, por exemplo. Em vez de uma identidade feminina, fala-se, neste contexto, em múltiplas identidades.

Butler desconfia de ações políticas fundada em identidades (fixas ou fluidas), pois, para ela, ao reforçarmos socialmente identidades corremos o riscos de reforçarmos também modos de exclusão (ou, como ela prefere, abjeção). Por exemplo, se definirmos a identidade feminina a partir de características biológicas e dissermos que, mulheres são diferentes dos homens, pois podem gerar vida, excluiremos mulheres estéreis e mulheres que decidiram não ter filhos. Se, em vez disto, utilizarmos o DNA como critério, excluiremos mulheres trans, travestis, intersexuais e aquelas que não se encaixam em qualquer categoria de gênero. Devemos estar atentos ao fato de que sempre que nos apoiamos em identidades criamos irreconhecibilidade ou, ainda, ininteligibilidade.

Butler (1999a) escreve:

A mobilização de categorias identitárias com o propósito de politização sempre permanece ameaçada pela possibilidade da identidade se tornar um instrumento de poder ao qual se opõe. Esta não é uma razão para não usar identidades e ser usado por elas. Não há posição política purificada do poder, e talvez esta impureza seja o que produz "agência", isto é, o potencial de interrupção e reversão de regimes regulatórios (p. xxvi). 
Ela não defende que a referência a identidades deslegitima por completo a ação política. Particularmente, em seus escritos mais recentes, concede que, por vezes, pode ser importante fazer um uso estratégico de identidades. Afirma, contudo, que há perigos ligados a esse modo de atuar. Movimentos sociais ou outros grupos políticos que reforçam identidades correm o risco de reproduzir a opressão que criticam. Por isso, a filósofa ressalta a importância da ampliação de coalizões políticas que não mais se sustentam em identidades.

Embora os discursos políticos que mobilizam categorias identitárias tendam a cultivar identificações em defesa de um objetivo político, pode ser que a persistência de desidentificações seja igualmente crucial para a rearticulação de contestações democráticas (BUTLER, 1993 p. 4.).

Adversários de Butler argumentam que seu projeto crítico negligencia o papel das lutas sociais como acontecem concretamente no tempo atual: se, hoje, grande parte dos grupos políticos se organizam por meio de identidades, a proposta de desidentificação poderia, no final das contas, provocar a desmobilização destes grupos.

Atenta a essas questões, Butler contra-argumenta e afirma que podemos observar atualmente alianças que se constituem mais em razão da resistência ao poder do que em razão de identidades e que, por isso, são capazes de dar lugar a indivíduos e grupos que guardam pouca ou nenhuma semelhança. Este tipo de coalizão pode tornar dessemelhanças produtivas: indivíduos ou grupos não precisam estar ligados por identidades para que possam trabalhar juntos. São alguns exemplos de alianças que desafiam padrões identitários: nos EUA, há grupos religiosos de gays e lésbicas que se opõem as restrições ao casamento homoafetivo; nos EUA e Europa, queers e imigrantes atuam conjuntamente contra limitações a cidadania e a direitos civis; há, em todo o mundo, coalizões que incluem grande diversidade de participantes, as quais defendem direito à saúde e à migração de pessoas com HIV positivo (BUTLER, 2009); no Brasil, podemos mencionar Ocupe Estelita em Recife, do qual podem participar 
todos os que se opõem a um modelo de desenvolvimento urbano assentado em uma concepção individualista.

Nesses casos e em muitos outros o que une sujeitos ou grupos é a força de resistência a operações de poder. Butler impulsiona, assim, uma investigação sobre normas que, sem que possamos perceber, fazem-nos reconhecer apenas os semelhantes e sobre uma ordem política que regula tais notas de semelhança.

\section{Referências:}

ADORNO, Theodor. Problems of Moral Philosophy. Cambridge: Polity Press, 2000.

BEAUVOIR, Simone. O Segundo Sexo: Fatos e Mitos. São Paulo: Difusão Européia do Livro, 1970.

BUTLER, Judith. Subjects of Desire: Hegelian Reflexions in Twentieth-Century France. New York: Columbia University Press, 1987

: Bodies that Matter: On The Discursive Limits of "Sex". New York \& London: Routledge, 1993.

. Excitable Speeches. New York: Routledge, 1997.

. Gender Trouble: Feminism and Subversion of Identity. New York \& London: Routledge, 1999a.

.A "Bad Writer" Bites Back. The New York Times, 1999b.

. On Speech, Race and Melancholia. Entrevista concedida à

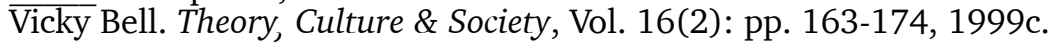

. Antigone's Claim: Kinship Between Life and Death. New York: Columbia Universty Press, 2000.

. What is Critique? An Essay on Foucault's Virtue. In David Ingram (ed). The political: Blackwell readings in continental philosophy. Oxford: Blackwell, 2002, pp. 212-228

. Undoing Gender. New York \& London: Routledge, 2004.

. Precarious Life: The Powers of Mourning and Violence. New York \& London: Verso, 2004b.

Press, 2005.

. Giving an Account of Oneself. New York: Fordham University

. Frames of War: When is Life Grievable? New York \& London: Verso, 2009.

\& Athena Athanasiou. Dispossesion: The Performative in The Political (Conversations with Athena Athanasiou). Cambridge: Polity Press, 2013. 
. Notes Toward a Performative Theory of Assembly. Cambridge \& London: Harvard University Press, 2015

COLLING, Leandro. Como pode a mídia ajudar na luta pelo respeito à diversidade sexual e de gênero. In: PELÜCIO, Larissa et al. (Org.). Olhares plurais para o cotidiano: gênero, sexualidade e mídia. Marília: Oficina Universitária; São Paulo: Cultura Acadêmica, 2012.

DERRIDA, Jacques. Limited Inc. Evanston: Northwestern University Press, 1988

HONNETH, Axel (2000a). Dezentriert Autonomie. Moralphilosophische Konsequenzen aus der Subjektkritik. In Axel Honneth. Das Andere der Gerechtigkeit. Aufsätze zur praktischen Philosophie.Frankfurt am Main: Suhrkamp, p. 237 - 254.

LACAN, Jacques. O Seminário. Livro 20. Mais, Ainda (1972-1973). Rio de Janeiro: Jorge Zahar Editor, 1985.

Lévi-Strauss, Claude. As Estruturas Elementares do Parentesco. Petrópolis: Vozes, 1982.

MANZI, Ronaldo; SCOFANO, Helgis. Ainda a Questão de Gênero - (In)Determinação ou Luta por Reconhecimento. Transformação vol.38 no.1 Marília, pp 29-42, Jan./Abr, 2015

NUSSBAUM, Martha. The Professor of Parody: The Hip Defeatism of Judith Butler. New Republic 22 Feb. 1999. pp. 37-45. Disponível em http://www.tnr.com/archive/0299/022299/nussbaum022299.html. Último acesso em janeiro/2011.

TAKARA, Samilo. Pode uma bicha comunicar? At(r)aques para uma Teoria da Comunicação Samilo Takara. Tríade, Sorocaba, SP, v. 5, n. 10, p. 18-32, dez. 2017 